\title{
Epidemiology of musculoskeletal tumors in Shiraz, south of Iran
}

\author{
Saeed Solooki, \\ Amir Reza Vosoughi, \\ Vahid Masoomi
}

Department of Orthopedic Surgery, Research Center for Bone and Joint Diseases, Chamran Hospital, Shiraz University of Medical Sciences, Shiraz, Iran

\begin{abstract}
A B S T R A C T
Background: Musculoskeletal tumors are rare, but their descriptive data in any region are important to reduce mortality rate and improve their management. Materials and Methods: Retrospectively, 426 pathologic reports from 1997 to 2008 were reviewed in Shiraz University Orthopedic Hospitals which are the main referral centers for musculoskeletal tumors in south of Iran. We collected and analyzed data on age, gender, anatomical site, and histopathologic types of musculoskeletal tumors. Results: Of the 426 cases, $60.1 \%$ were men and $39.9 \%$ were women. The commonest malignant bone tumors were osteosarcoma $(89 ; 50.6 \%)$, metastasis $(30 ; 17.0 \%)$, Ewing's sarcoma $(28 ; 15.9 \%)$, and chondrosarcoma $(14 ; 8.0 \%)$. The most frequent benign bone tumors were osteochondroma $(136 ; 63.9 \%)$, enchondroma $(23 ; 10.8 \%)$, giant cell tumor $(21$; $9.9 \%)$, and osteoid osteoma $(14 ; 6.6 \%)$. The femur was the most commonly involved site in musculoskeletal tumors. It was followed by the tibia in benign tumors and the humerus in malignant ones. Metastasis $(28 ; 32.6 \%)$, soft tissue tumors $(18 ; 20.9 \%)$, osteochondroma $(10 ; 11.6 \%)$, and osteosarcoma $(9 ; 10.5 \%)$ were the most diagnosed bone lesions in patients older than 40. Conclusion: There are no significant changes in epidemiology of musculoskeletal tumors in Shiraz, south of Iran, in comparison with other parts of the world.
\end{abstract}

Key words: Benign, bone, Iran, malignancy, musculoskeletal, Shiraz, tumor

\section{INTRODUCTION}

Malignant neoplasms are one of the main causes of mortality in the world. Skeletal system involvement as metastasis is common. The primary source comes usually from breast, prostate, kidney, lung, and thyroid. ${ }^{[1,2]}$ Diagnosis of these lesions often changes the treatment plan.

Primary bone tumors are rare. They account for $0.2-0.5 \%$ of all malignancies in all ages ${ }^{[3]}$ and comprise $3-5 \%$ of tumors diagnosed in European children below 15 years and $7-8 \%$ in adolescents between 15 and 19 years of age. ${ }^{[4]}$ Incidence of primary malignant bone tumors is about 9 in 1 million people in a year. It is slightly higher in males than females (10/million/year vs. $8 /$ million/year). ${ }^{[5]}$ It is usual for these tumors to be diagnosed late because these neoplasms are uncommon; moreover, their presentations

\begin{tabular}{|l|l|}
\hline \multicolumn{3}{|c|}{ Access this article online } \\
\hline Quick Response Code: & Website: \\
\hline & www.jmpo.org \\
\hline
\end{tabular}

are vague with unspecific signs and symptoms. Sometimes they are recognized and treated like osteomyelitis or simple fracture before exact diagnosis. Therefore, basic epidemiology in each region can help doctors to diagnose and manage them earlier. Also, these studies can guide researchers to find particular risk factors in that area.

According to previous researches, distribution of primary bone tumors is variable in different parts of the world. Highest rates are seen in Europe and the USA, but Asian countries have lower incidence and prevalence. ${ }^{[4,6,7]}$ Although there are several epidemiologic studies of musculoskeletal tumors in the neighboring countries of Iran, ${ }^{[8-11]}$ to the best of our knowledge, this report is the first documented one in Iran.

\section{MATERIALS AND METHODS}

We reviewed retrospectively charts and pathologic reports of patients who had undergone musculoskeletal open or excisional biopsies from January 1997 to December 2008. Biopsies had been taken in Chamran and Namazi Hospitals of Shiraz University of Medical Sciences, two main referral centers in the south of Iran. Pathologic slides had been reported by three expert pathologists in 
musculoskeletal diseases. Also, final diagnosis had been correlated with clinical presentation and radiograph findings by an orthopedic tumor surgeon (senior author). It should be mentioned that although diagnosis of several bone tumors like osteoid osteoma, osteochondroma, and nonossifying fibroma was made clinically and radiographically, open biopsies had been taken due to equivocal diagnosis. Moreover, some reports were the result of excisional biopsies (like osteochondroma and osteoid osteoma). We collected data on age, sex, anatomical site, and histopathologic type of 426 patients.

On the basis of pathologic reports, the tumors were classified as benign bone tumors, malignant bone tumors, and soft tissue tumors. The latter comprised malignant ones like rhabdomyosarcoma, fibrosarcoma, etc. Benign soft tissue tumors were excluded. There were some nonspecific sarcomas like small cell malignant sarcoma and high-grade malignant sarcoma in pathologic reports. We classified them as others in the results.

Description statistics were performed using SPSS software version 18.0 for windows (SPSS Inc., Chicago, IL, USA). Frequency and percentage of the mentioned variables were calculated.

\section{RESULTS}

Totally, 426 cases were analyzed. Male to female ratio was 1.5. There were 170 women (39.9\%) and 256 men (60.1\%). The oldest patient was an 84 -year-old man with metastasis. There were two 4-year-old children as the youngest patients, with pathologic reports of osteofibrous dysplasia and soft tissue tumor. As shown in Table 1, 176 patients had malignant bone tumors with the peak frequency seen in patients of age between 5 and 25 years. Also, large proportion of benign bone tumors $(161 ; 75.5 \%)$ was seen in patients younger than 25 years of age. Soft tissue tumors occurred more $(10 ; 27.1 \%)$ in the age group of $45-54$ years.

Overall, the most common pathologic types of bone tumors were osteochondroma $(136 ; 35.0 \%)$ and osteosarcoma (89; $22.9 \%)$. The femur $(159 ; 40.9 \%)$ was the most common anatomical site of bone tumors, followed by the tibia (84; $21.6 \%)$, and the humerus $(52 ; 13.4 \%)$.

\section{Benign bone tumors}

As illustrated in Table 2, osteochondroma (136; 63.9\%), enchondroma $(23 ; 10.8 \%)$, and giant cell tumors (21; $9.9 \%$ ) were the most frequent. Men outnumbered women with respect to osteochondroma and enchondroma [Table 3]. This is in contrast to giant cell tumor, wherein $76.2 \%$ cases were women. Also, about half of the cases of osteochondroma and enchondroma belonged to 15-24 years (48.5\% for osteochondroma and 56.3\% for enchondroma). Giant cell tumors were seen mostly in adult patients (third and fourth decades of life).

\section{Malignant bone tumors}

Of a total of 176 malignant neoplasms, osteosarcoma was the commonest $(84 ; 50.6 \%)$, followed by metastasis $(30$; $17.0 \%)$, Ewing's sarcoma $(28 ; 15.9 \%)$, and chondrosarcoma $(14 ; 8.0 \%)$ [Table 2]. Osteosarcoma and Ewing's sarcoma occurred in males more than females. Male to female ratios were about 1.3 and 6 for osteosarcoma and Ewing's sarcoma, respectively. Both were more frequent in the 15- to 24-year age group. There was no case of Ewing's sarcoma in patients older than 34 years of age [Table 3].

\section{Soft tissue tumors}

There were 37 cases with malignancy of soft tissues, with a male predilection (22; 59.5\%). The commonest anatomical locations were the thigh $(11 ; 29.7)$, leg $(7$; $18.4 \%)$, wrist-hand $(7 ; 18.9 \%)$, and foot $(5 ; 13.5 \%)$.

\section{Musculoskeletal tumors in patients over $\mathbf{4 0}$ years}

Of 86 patients, 44 (51.2\%) were men and 42 (48.8\%) were women. Metastasis was the leading pathologic report (28; $32.6 \%)$, followed by soft tissue tumors $(18 ; 20.9 \%)$. The most diagnosed benign and malignant bone tumors were osteochondroma $(10 ; 11.6 \%)$ and osteosarcoma (9; 10.5\%) [Table 4].

\section{Anatomical site distribution}

Overall, the femur was the most commonly involved long bone. It was followed by the humerus $(34 ; 19.3 \%)$ and the tibia $(25 ; 14.2 \%)$ in malignant bone tumors, and by the tibia $(59,27.6 \%)$ and the wrist-hand $(27 ; 12.7 \%)$ in benign neoplasms. Anatomical site distribution of specific tumors is illustrated in Table 5. Of 35 patients with musculoskeletal tumors in wrist and hand, 4 occurred in

\begin{tabular}{|c|c|c|c|c|c|c|c|c|c|}
\hline \multirow[t]{2}{*}{ Type } & \multicolumn{9}{|c|}{ Age (years) } \\
\hline & $0-4(\%)$ & $5-14(\%)$ & $15-24(\%)$ & $25-34(\%)$ & $35-44(\%)$ & $45-54(\%)$ & $55-64(\%)$ & $>65(\%)$ & Total (\%) \\
\hline Malignant bone tumors & $0(0.0)$ & $37(21.0)$ & $75(42.6)$ & $9(5.1)$ & $17(9.7)$ & $15(8.5)$ & $7(4.0)$ & $16(9.1)$ & $176(100.0)$ \\
\hline Benign bone tumors & $1(0.5)$ & $64(30.0)$ & $96(45.0)$ & $21(9.9)$ & $15(7.0)$ & $10(4.7)$ & $5(2.4)$ & $1(0.5)$ & $213(100.0)$ \\
\hline Soft tissue tumors & $1(2.7)$ & $3(8.1)$ & $5(13.5)$ & $8(21.6)$ & $4(10.8)$ & $10(27.1)$ & $4(10.8)$ & $2(5.4)$ & $37(100.0)$ \\
\hline Total & $2(0.4)$ & $104(24.4)$ & $176(41.3)$ & $38(8.9)$ & $36(8.4)$ & $35(8.2)$ & $16(3.7)$ & $19(4.7)$ & $426(100.0)$ \\
\hline
\end{tabular}


Table 2: Frequency and percentage of each bone tumor

\begin{tabular}{|c|c|c|c|c|c|}
\hline & \multicolumn{2}{|c|}{ Malignant } & & \multicolumn{2}{|c|}{ Benign } \\
\hline & Number & Percentage & & Number & Percentage \\
\hline Osteosarcoma & 89 & 50.6 & Osteochondroma & 136 & 63.9 \\
\hline Metastasis & 30 & 17.0 & Enchondroma & 23 & 10.8 \\
\hline Ewing's sarcoma & 28 & 15.9 & Giant cell tumors & 21 & 9.9 \\
\hline Chondrosarcoma & 14 & 8.0 & Osteoid osteoma & 14 & 6.6 \\
\hline Others & 11 & 6.2 & Chondroblastoma & 11 & 5.2 \\
\hline Lymphoma & 2 & 1.1 & Osteoblastoma & 2 & 0.9 \\
\hline Plasmacytoma & 1 & 0.6 & Fibrous dysplasia & 2 & 0.9 \\
\hline Adamantinoma & 1 & 0.6 & Chondromyxoid fibroma & 2 & 0.9 \\
\hline \multirow[t]{2}{*}{ Total } & 176 & 100.0 & Non ossifying fibroma & 2 & 0.9 \\
\hline & & & Total & 213 & 100.0 \\
\hline
\end{tabular}

\begin{tabular}{lcccccccccccc}
\hline \multicolumn{10}{l}{ Table 3: Distribution of the commonest tumors by gender and age } \\
\hline Type & Female & Male & $0-4$ & $5-14$ & $15-24$ & $25-34$ & $35-44$ & $45-54$ & $55-64$ & $>65$ & Total \\
Osteochondroma & $51(37.5)$ & $85(62.5)$ & $0(0.0)$ & $49(36.0)$ & $66(48.5)$ & $5(3.7)$ & $7(5.2)$ & $5(3.7)$ & $40(2.9)$ & $0(0.0)$ & $136(100.0)$ \\
Enchondroma & $9(39.1)$ & $14(60.9)$ & $0(0.0)$ & $1(4.4)$ & $13(56.3)$ & $4(17.4)$ & $2(8.7)$ & $1(4.4)$ & $1(4.4)$ & $1(4 \cdot 4)$ & $23(100.0)$ \\
Giant cell tumors & $16(76.2)$ & $5(23.8)$ & $0(0.0)$ & $1(4.8)$ & $4(19.0)$ & $9(42.9)$ & $3(14.3)$ & $4(19.0)$ & $0.0(0.0)$ & $00(0.0)$ & $21(100.0)$ \\
Osteosarcoma & $39(43.8)$ & $50(56.2)$ & $0(0.0)$ & $25(28.1)$ & $48(54.0)$ & $4(4.5)$ & $4(4.5)$ & $2(2.2)$ & $2(2.2)$ & $4(4.5)$ & $89(100.0)$ \\
Ewing's sarcoma & $4(14.3)$ & $24(85.7)$ & $0(0.0)$ & $10(35.7)$ & $17(60.7)$ & $1(3.6)$ & $0(0.0)$ & $0(0.0)$ & $0(0.0)$ & $0(0.0)$ & $28(100.0)$ \\
\hline
\end{tabular}

Figures in parentheses are in percentage

\begin{tabular}{lcc}
\hline $\begin{array}{l}\text { Table 4: Frequency and percentage of } \\
\text { musculoskeletal tumors in patients older } \\
\text { than } \mathbf{4 0}\end{array}$ & Frequency & Percentage \\
\hline Type & 28 & 32.6 \\
Metastasis & 18 & 20.9 \\
Soft tissue tumors & 10 & 11.6 \\
Osteochondroma & 9 & 10.5 \\
Osteosarcoma & 6 & 6.9 \\
Chondrosarcoma & 6 & 6.9 \\
Giant cell tumor & 4 & 4.7 \\
Enchondroma & 3 & 3.5 \\
Others & 1 & 1.2 \\
Chondromyxoid fibroma & 1 & 1.2 \\
Plasmacytoma & 86 & 100.0 \\
Total & &
\end{tabular}

carpus bones, 8 in metacarpal bones, and 23 in phalanges. The commonest involved finger was the second one $(8 ; 34.7 \%)$.

There are some cases with involvement of more than one bone:

1. Three cases with osteochondroma of femur and tibia

2. A case of osteosarcoma of tibia with skip lesion in femur

3. A 19-year-old man with diagnosis of Ewing's sarcoma involved humerus and ulna

4. An adolescent girl with osteoid osteoma involved tibia and first metatarsal

5. A case of metastatic carcinoma to scapula and ulna

\section{DISCUSSION}

Primary bone tumors, comprising less than $1 \%$ of all malignancies, ${ }^{[3,11]}$ have a high mortality rate. The relative 5-year survival rate is $53.9 \%$ for osteosarcoma, $75.2 \%$ for chondrosarcoma, and 50.6\% for Ewing's sarcoma. ${ }^{[12]}$ Description data and regional distribution of musculoskeletal tumors, as a cause of significant number of deaths, are important for improvement in diagnosis and treatment strategies.

Osteosarcoma is the most common primary malignancy according to several studies. ${ }^{[5,13-17]}$ It is reported to constitute about $35-68 \%$ of all primary malignant bone tumors. ${ }^{[8,9,15-17]}$ In our study, osteosarcoma accounted for $50.6 \%$ of patients. Male to female ratio was about 1.3, which is the same as that reported in other studies. ${ }^{[4,18]}$ It commonly affects individuals in their first three decades of life. According to this study, none of the patients were less than 5 years of age and the highest number of patients $(73 ; 82.1 \%)$ was below 25 years of age. Ewing's sarcoma accounted for $15.9 \%$ of all malignant tumors, making it the second most common primary malignancy in bone. Chondrosarcoma was the third $(14 ; 8.0 \%)$. Our results are similar to those reported in a study by Rao et al..$^{10]}$ in India and by Shah et al. ${ }^{[8]}$ in Pakistan. Most reports from developed countries explain chondrosarcoma as the second most frequent. ${ }^{[15,16]}$ Ewing's sarcomas are tumors of the young, with $80 \%$ occurring in patients under 20 years. They rarely occur above the age of $30 .{ }^{[5]}$ We did not have any Ewing's sarcoma patient older than 35 years. 
Solooki, et al.: Epidemiology of musculoskeletal tumors in Shiraz

\begin{tabular}{|c|c|c|c|c|c|c|c|c|}
\hline Site & $\begin{array}{l}\text { Malignant } \\
\text { tumors }\end{array}$ & Osteosarcoma & Metastasis & $\begin{array}{l}\text { Ewing's } \\
\text { sarcoma }\end{array}$ & $\begin{array}{l}\text { Benign } \\
\text { tumor }\end{array}$ & Osteochondroma & Enchondroma & $\begin{array}{c}\text { Giant cell } \\
\text { tumors }\end{array}$ \\
\hline Femur & $84(47.6)$ & $44(49.5)$ & $21(70.0)$ & $10(35.7)$ & $71(33.3)$ & $54(39.7)$ & $0(0.0)$ & $7(33 \cdot 3)$ \\
\hline Tibia & $25(14.2)$ & 15 (16.9) & $0(0.0)$ & $5(17.9)$ & $59(27.6)$ & $35(25.7)$ & $2(8.7)$ & $6(28.6)$ \\
\hline Femur-tibia & $1(0.6)$ & $1(1.1)$ & $0(0.0)$ & $0(0.0)$ & $3(1.4)$ & $3(2.2)$ & $0(0.0)$ & $\mathrm{o}(0.0)$ \\
\hline Fibula & $5(2.8)$ & $5(5.6)$ & $0(0.0)$ & $0(0.0)$ & $3(1.4)$ & $3(2.2)$ & $0(0.0)$ & $0(0.0)$ \\
\hline Foot & $1(0.6)$ & $0(0.0)$ & $0(0.0)$ & $0(0.0)$ & $12(5.6)$ & $7(5.1)$ & $3(13.1)$ & $1(4.8)$ \\
\hline Tibia-foot & $0(0.0)$ & $0(0.0)$ & $0(0.0)$ & $0(0.0)$ & $1(0.5)$ & $0(0.0)$ & $0(0.0)$ & $0(0.0)$ \\
\hline Scapula & $10(5.7)$ & $3(3.4)$ & $0(0.0)$ & $1(3.6)$ & $4(1.9)$ & $4(3.0)$ & $0(0.0)$ & $0(0.0)$ \\
\hline Humerus & $34(19 \cdot 3)$ & $17(19.1)$ & $5(16.8)$ & $7(25.0)$ & $18(8.5)$ & $15(11.0)$ & $0(0.0)$ & $0(0.0)$ \\
\hline Radius & $1(0.6)$ & $1(1.1)$ & $0(0.0)$ & $0(0.0)$ & $8(3.8)$ & $4(3.0)$ & $1(4 \cdot 3)$ & $3(14 \cdot 3)$ \\
\hline Ulna & $6(3.4)$ & $2(2.2)$ & $1(3.3)$ & $2(7.1)$ & $4(1.9)$ & $2(1.5)$ & $0(0.0)$ & $2(9.5)$ \\
\hline Scapula-ulna & $1(0.6)$ & $0(0.0)$ & $1(3.3)$ & $0(0.0)$ & $0(0.0)$ & $0(0.0)$ & $0(0.0)$ & $0(0.0)$ \\
\hline Humerus-ulna & $1(0.6)$ & $0(0.0)$ & $0(0.0)$ & $1(3.6)$ & $0(0.0)$ & $0(0.0)$ & $0(0.0)$ & $0(0.0)$ \\
\hline Hand & $1(0.6)$ & $0(0.0)$ & $1(3.3)$ & $0(0.0)$ & $27(12.7)$ & $7(5.1)$ & $17(73.9)$ & $2(9.5)$ \\
\hline Pelvis-vertebra & $6(3.4)$ & $1(1.1)$ & $1(3.3)$ & $2(7.1)$ & $3(1.4)$ & $2(1.5)$ & $0(0.0)$ & $0(0.0)$ \\
\hline Total & $176(100.0)$ & $89(100.0)$ & $30(100.0)$ & $28(100.0)$ & $213(100.0)$ & $136(100.0)$ & $23(100.0)$ & $21(100.0)$ \\
\hline
\end{tabular}

Figures in parentheses are in percentage

In our study, the most frequent benign bone tumor was osteochondroma, followed by enchondroma and giant cell tumor. Osteochondroma accounted for $63.9 \%$ of benign bone tumors and $35 \%$ of all bone neoplasms. The femur and the tibia were the most affected anatomical sites. The highest percentage of osteochondroma has been reported in our series among all the reviewed papers. ${ }^{[10,15,19]}$ The real frequency of this tumor may be more in our population because of its clinical diagnosis by radiographs. Only excisional biopsies were included in study. The second most frequent benign neoplasm, enchondroma, accounted for about $11 \%$ of cases, wherein $73.9 \%$ cases were diagnosed in hand. Foot was the next most common site. Giant cell tumors, as the second most common benign tumors in several studies, ${ }^{[15,19]}$ represent about $5 \%$ of all bone tumors. ${ }^{[20]}$ In our study, it was seen in 21 patients $(9.9 \%)$ with involvement of the femur $(33.3 \%)$, the tibia $(28.6 \%)$, and the radius $(14.3 \%)$ in order of frequency.

Metastasis from other sites ${ }^{[1,2]}$ and multiple myeloma are the most likely diagnosed bone lesions in patients older than 40. ${ }^{[21]}$ We had only one case of plasmacytoma. This may be due to its clinical diagnosis by internists and oncologists without biopsy taking. Metastatic carcinoma and soft tissue tumors were the most prevalent diagnosed bone tumors in older patients. Osteochondroma $(10 ; 11.6 \%)$ and osteosarcoma $(9 ; 10.5 \%)$ were the common primary benign and malignant bone tumors, respectively. Interestingly, bone fibrous tumors were very rare in our study.

There are reasons to explain late diagnosis with poor prognosis of musculoskeletal tumors. Besides the rarity of musculoskeletal tumors and unfamiliarity of general medical staff, they present with nonspecific clinical symptoms. Swelling and pain are seen in other musculoskeletal diseases which are more common than tumors. Epidemiologic studies help in rapid diagnosis and management. Overall, there is not any significant difference between our study and others in literature.

\section{REFERENCES}

1. Coleman RE. Clinical features of metastatic bone disease and risk of skeletal morbidity. Clin Cancer Res 2006;12:6243s-9s.

2. Lewis VO. What's new in musculoskeletal oncology. J Bone Joint Surg Am 2007;89:1399-407.

3. Fletcher CD, Unni KK, Mertens F, editors. Pathology and genetics of tumours of soft tissue and bone. Vol. 5 of World Health Organization classification of tumours. Lyon, France: IARC Press, 2002.

4. Stiller CA, Bielack SS, Jundt G, Steliarova-Foucher E. Bone tumours in European children and adolescents, 1978-1997. Report from the Automated Childhood Cancer Information System project. Eur J Cancer 2006;42:2124-35.

5. Bramer JA, Somford MP. The epidemiology of primary skeletal malignancy. Orthop Trauma 2010;24:247-51.

6. Parkin DM, Stiller CA, Nectoux J. International variations in the incidence of childhood bone tumours. Int J Cancer 1993;53: 371-6.

7. Eyre R, Feltbower RG, Mubwandarikwa E, Eden TO, McNally RJ. Epidemiology of bone tumours in children and young adults. Pediatr Blood Cancer 2009;53:941-52.

8. Shah SH, Muzaffar S, Soomro IN, Pervez S, Hasan SH. Clinico-morphological pattern and frequency of bone cancer. J Pak Med Assoc 1999;49:110-2.

9. Omololu AB, Ogunbiyi JO, Ogunlade SO, Alonge TO, Adebisi A, Akang EE. Primary malignant bone tumour in a tropical African University teaching hospital. West Afr J Med 2002;21:291-3.

10. Rao VS, Pai MR, Rao RC, Adhikary MM. Incidence of primary bone tumours and tumour like lesions in and around Dakshina Kannada district of Karnataka. J Indian Med Assoc 1996;94: 103-4.

11. Yeole BB, Jussawalla DJ. Descriptive epidemiology of bone cancer in greater Bombay. Indian J Cancer 1998;35:101-6. 
12. Damron TA, Ward WG, Stewart A. Osteosarcoma, chondrosarcoma, and Ewing's sarcoma: National Cancer Data Base Report. Clin Orthop Relat Res 2007;459:40-7.

13. Ritter J, BielackSS. Osteosarcoma. Ann Oncol2010;21 Suppl 7: vii320-5.

14. Buckley JD, Pendergrass TW, Buckley CM, Pritchard DJ, Nesbit ME, Provisor AJ, et al. Epidemiology of osteosarcoma and Ewing's sarcoma in childhood: A study of 305 cases by the Children's Cancer Group. Cancer 1998;83:1440-8.

15. Baena-Ocampo Ldel C, Ramirez-Perez E, Linares-Gonzalez LM, Delgado-Chavez R. Epidemiology of bone tumors in Mexico City: Retrospective clinicopathologic study of 566 patients at a referral institution. Ann Diagn Pathol 2009;13:16-21.

16. Blackwell JB, Threlfall TJ, McCaul KA. Primary malignant bone tumours in Western Australia, 1972-1996. Pathology 2005;37:278-83.

17. Settakorn J, Lekawanvijit S, Arpornchayanon O, Rangdaeng S, Vanitanakom P, Kongkarnka S, et al. Spectrum of bone tumors in Chiang Mai University Hospital, Thailand according to WHO classification 2002: A study of 1,001 cases. J Med Assoc Thai 2006;89:780-7.

18. Stiller CA, Craft AW, Corazziari I. Survival of children with bone sarcoma in Europe since 1978: Results from the EUROCARE study. Eur J Cancer 2001;37:760-6.

19. Odetayo OO. Pattern of bone tumours at the National Orthopaedic Hospital, Lagos, Nigeria. West Afr J Med 2001;20:161-4.

20. Turcotte RE. Giant cell tumor of bone. Orthop Clin North Am 2006;37:35-51.

21. Heck RK. General principles of tumors. In: Canale ST, Beaty JH, editors. Campbell's Operative Orthopaedics. $11^{\text {th }}$ ed. Philadelphia: Mosby, Elsevier: 2008. p. 775-854.

How to cite this article: Solooki S, Vosoughi AR, Masoomi V. Epidemiology of musculoskeletal tumors in Shiraz, south of Iran. Indian J Med Paediatr Oncol 2011;32:187-91.

Source of Support: Nil, Conflict of Interest: None declared.

\section{Android App}

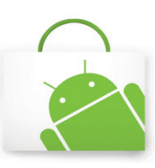

A free application to browse and search the journal's content is now available for Android based mobiles and devices. The application provides "Table of Contents" of the latest issues, which are stored on the device for future offline browsing. Internet connection is required to access the back issues and search facility. The application is compatible with all the versions of Android. The application can be downloaded from https://market.android.com/details?id=comm.app.medknow. For suggestions and comments do write back to us. 